\title{
İşlevini yitirmiş endüstriyel peyzajların yeniden işlevlendirilmesi: Sümerbank Kayseri Bez Fabrikası örneği
}

\section{Re-functionalizing of post-Industrial landscapes: the case study of Sumerbank Kayseri cloth factory}

\author{
Aslıhan TIRNAKÇI
}

Nevşehir Hacı Bektaş Veli Üniversitesi, Mühendislik-Mimarlık Fakültesi, Peyzaj Mimarlığı Bölümü, Nevşehir, Türkiye

\section{Eser Bilgisi / Article Info}

Araştırma makalesi / Research article DOI: $10.17474 /$ artvinofd.633718

Sorumlu yazar / Corresponding author Aslıhan TIRNAKÇI

e-mail: aslihanerdogan@nevsehir.edu.tr

Geliş tarihi / Received

16.10.2019

Düzeltme tarihi / Received in revised form

20.12.2019

Kabul Tarihi /Accepted

05.02.2020

Elektronik erişim / Online available

12.03.2020

Anahtar kelimeler:

Endüstriyel peyzaj

Yeniden işlevlendirme

Sümerbank Kayseri Bez Fabrikası

Abdullah Gül Üniversitesi

\section{Keywords:}

Postindustrial landscape

Re-functionalization

Sümerbank Kayseri Cloth Factory

Abdullah GÜL University

\begin{abstract}
Özet
Son yıllarda, kent içerisinde ömrünü yitirmiş endüstriyel peyzaj alanları kentsel dönüşüm projeleri kapsamında çeşitli ölçeklerde rekreasyon, ekolojik ve ekonomik amaçları kapsayan sürdürülebilir plan kararlarıyla yeniden işlevlendirilmektedir. Yeniden işlevlendirme, kent içi çöküntü alanların korunması ve kültürel sürekliliğinin sağlanmasındaki temel taşı oluşturmaktadır. Doğru yeniden işlevlendirme çalışmaları ile endüstriyel peyzaj alanları gelecek nesillere aktarılabilir. Bu çalışmada, Cumhuriyet Dönemi'nin öncü sanayi kuruluşlarından biri olan Sümerbank Kayseri Bez Fabrikası'nın, yeniden işlevlendirme kapsamında dönüştürüldüğü Abdullah Gül Üniversitesi Sümer Kampüsü, sanayi sonrası peyzajların yeniden işlevlendirilmesinde kullanılan tasarım ilkeleri ve stratejileri çerçevesinde yapılan gözlemler sonucu analiz edilmiş, bir öneri çizelgesi oluşturulmuştur.
\end{abstract}

\begin{abstract}
In recent years, post-industrial landscape areas, which have been located in the city center, have been re-functionalized within the scope of urban regeneration with sustainable plan decisions such as a broad array of recreational, ecological, and economic development objectives at various scales. Refunctioning of brownfield areas is keystone of providing protection and cultural sustainability of urban collapsed areas. With correct re-functionalization industrial landscape areas can be transferred to future generations. In this study, Abdullah Gül University Sumer Campus, which is one of the first important industrial corporations of republican period and transformed within a re-functionalization of Sümerbank Kayseri Cloth Factory were analyzed within the scope of design principles and strategies used in redevelopment of post-industrial landscapes and their contribution to the urban landscape was evaluated and a suggestion form was created.
\end{abstract}

\section{GiRiş}

Sanayi devrimi ile başlayan kentsel dönüşümlerin kent kimliğini yok etmesi ile kültürel miras kavramı ortaya çıkmıştır. Zamanla kültürel mirasın kapsamı genişlemiş ve kültürel mirasın yeni bir boyutu olarak "endüstriyel miras" kavramı ortaya çıkmıştır (Kariptaş 2010). Tahrip olmuş bir maden ocağı veya bir fabrika kültürel mirasın bir parçası olmaktan çok medeniyetin bir parçası olarak görülmüş (Soyez 2002), ve işlevini yitirmiş endüstriyel alanlar kültürel mirasın bir parçası haline gelmiştir.

Endüstri kültürünün tarihi, teknolojik, mimari, sosyokültürel ve bilimsel değer taşıyan kalıntılarına endüstriyel miras denir (Anonymous 2003). Endüstriyel miras alanlarının üretim yapıları ve birimlerini (depo, ambar vb.), üretim ve nakil komplekslerini, ibadethane ve eğitim gibi sosyal aktivite alanlarını içerdiği görülmektedir (Cossons 1993, Anonymous 2003).

Post modern kentleşmenin başlaması ve teknolojideki hızlı değişim ile birlikte yeni iş kolları ortaya çıkmış, yüzlerce kişinin çalıştığı dev fabrikaların bulunduğu üretim kentleri yerlerini tüketim toplumlarına bırakmıştır. Sanayi kentlerinde endüstriyel yapıların kent merkezinden uzaklaşması ile birlikte kentlerde yeni bir mekânsal yapılanma başlamıştır. Anıtsal veya sivil-mimari yapılar gibi karakteristik mimari özellikleri olmayan bu yapılar ve çevreleri estetik değeri olmayan yapılar ve alanlar olarak görülmüş, kentsel alanlarda yeni mekânsal planlamalar sonucu yeniden kullanıma "dönüşüm"e başlanmıştır (Föhl 1995, Tolga 2006). Dünya genelinde uygulanan 346 kentsel dönüşüm projesinin 139'u 
endüstriyel peyzaj kapsamında değerlendirilen yeniden işlevlendirme projeleridir (Loures ve ark. 2008, 2011). Bu bağlamda kentsel dönüşüm/yenileme projeleri önem kazanmıştır. Özellikle kullanımını yitirmiş, kent içinde kalmış endüstriyel alanlar kente, halka, sürdürülebilir kullanım kapsamında doğayla ve kentin dokusuyla içi içe olacak şekilde kazandırılması, kent içi çöküntü alanlarının dönüşümü (endüstriyel dönüşüm) olarak ifade edilmektedir (Koçan 2011, Görgülü 2009, Dağ ve Özberk 2012).

Kent içi çöküntü alanları (Esmer Alan/Brownfield) şu şekilde tanımlamaktadır:

- Sınırlandırılmış alan ya da yerleşkelerin önceki kullanımından etkilenmiş,

- Terkedilmiş veya atıl durumda olan,

- Gelişmiş veya kısmen gelişmiş kentlerde bulunan,

- İşlevsel kullanıma sahip olabilmesi için birtakım girişimlere intiyaç duyulan,

- Endüstriyel kaynaklı kirliliğe ya da çevresel kirliliğe maruz kalmış alanlar (Anonim, 2019a).

Kentlerdeki benzin istasyonları, endüstriyel sanayi alanları (ilaç sanayisi, elektronik sanayisi, otomobil, kimya sanayisi) demiryolu hatları, tekstil fabrika alanları, askeri depolama alanları Esmer Alan (Brownfield) olarak nitelendirilen alanlardır (Kirkwood ve ark. 2010).

Endüstriyel alanlar faaliyetleri sırasında içinde bulundukları kente ekonomik, sosyal, görsel anlamda katkı sağladıkları gibi faaliyetleri sonlandıktan sonra çoğu zaman terk edilmekte, atıl halde bırakılmaktadırlar (Kaya ve ark. 2015). Kentsel peyzaj içerisinde atıl ve işlevsiz kalan bu alanların gerek alan büyüklükleri gerekse kültürel potansiyelleri oldukça önemlidir.

Son yıllarda işlevlerini yitirmiş endüstriyel miras alanlarına kentin sosyo-kültürel gereksinimleri doğrultusunda müze, kültür merkezi, sanat galerisi vb. fonksiyonlar yüklenerek yeniden kentsel peyzaja kazanımları sağlanmaktadır. Ancak endüstriyel miras olarak yapılar tek başlarına ele alındıklarında ait olduğu dönemin sosyo-kültürel boyutunu tam olarak yansıtmayabilirler (Kariptaş Seçer ve Altuncu 2009). Bu nedenle yapılar çevreleri ile birlikte ele alınmalı, kentle ve kentli ile bütünleşmelidir.
Bu çalışmada üretim amacı ile kullanılmayan Sümerbank Kayseri Bez Fabrikası'nın endüstriyel peyzaj kavramı çerçevesinde mekânsal olarak nasıl kullanıldığı, ne tür işlevsel bir dönüşümle kentsel peyzaja kazandırıldığı irdelenmiş, endüstri miras alanının koruma-kullanma dengesi kapsamında sürdürülebilirliğinin sağlanmasına yönelik öneriler getirilmiş ve kent yaşamına sağladığı katkılar üzerinde durulmuştur.

\section{MATERYAL ve YÖNTEM}

\section{Materyal}

Çalışmanın ana materyalini Erken Cumhuriyet Dönemi'nde yapılmış Sümerbank Kayseri Bez Fabrikası yerleşkesi oluşturmaktadır. Yerleşke, kent kültürünün ve ulusal kimliğin oluşmasındaki rolü ve öneminden dolayı, 2003 yılı sonunda anıt olarak belirlenmiş ve koruma altına alınmıştır (Asiliskender ve Baturay Yöney 2018). Yerleşke $1.122 .820 \mathrm{~m}^{2}$ lik bir araziye sahiptir. İplik, dokuma ve terbiye binalarını içeren işletme binalarına ait alan 29.680 $\mathrm{m}^{2}$ 'lik alanı oluştururken, termik santral, atölyeler, ambarlar, kömür sahası, garaj ve yemekhaneler gibi birimlere ait alan ise $81.400 \mathrm{~m}^{2 \prime}$ lik alanı oluşturmaktadır (Anonim 1991). Fabrika modernleşme ve sanayileşme hedefi ile Türkiye Cumhuriyeti Devleti'nin inşa ettiği ilk sanayi kuruluşudur. Fabrika, Türkiye'nin modern mimarlık örnekleri arasında ilk sıralarda yer almaktadır

Çalışmada yardımcı materyal olarak konu ile ilgili literatürlerden, Abdullah Gül Üniversitesi Yapı İşleri ve Teknik Daire Başkanlığı'ndan elde edilen bilgi ve belgelerden, yerinde yapılan gözlem ile tutulan notlar ve çekilen fotoğraflardan faydalanılmıştır.

\section{Yöntem}

Çalışma yöntemi veri toplama, analiz ve değerlendirme aşamalarından oluşmaktadır. ilk olarak Sümerbank Kayseri Bez Fabrikası'nın kentsel dokundaki yeri ve alan kullanım yapısı hakkında bilgi verilmiştir. Master Planı, çalışma konusu ile ilgili yapılan araştırmalar irdelenmiş, alanda yapılan gözlemler ile birlikte alanın dönüşümü kapsamında mevcut kullanımına yönelik bütünleşik bir değerlendirme yapılmıştır. Değerlendirme aşamasında yapısal dönüşümler yerine özellikle dış mekân kullanımı 
(yapı ve çevresi birlikte) ele alınmıştır. Daha sonra çalışma alanının yeniden kentle bütünleşmesini değerlendirebilmek ve genel bir veri oluşturabilmek için Loures ve ark. (2008) temel altlık olarak kullanılmış, bu bağlamda endüstriyel miras kapsamında ele alınan eski sanayi bölgelerinin peyzaj tasarımı konusunda belirlediği 35 adet tasarım ilkesi yol gösterici olmuştur. Çalışmada bu kriterlerin kullanılmasındaki amaç kentsel dönüşüm kapsamında endüstriyel peyzaj alanlarına ait kentsel açık alanların yeniden işlevlendirilmesi ve kentle ilişkilendirilmesine bir ara kesit oluşturmasıdır. Çünkü belirlenen bu ilkeler atıl durumda bulunan endüstriyel peyzaj alanlarının yeniden kentsel peyzajla bütünleşmesi açısından algılanabilir ve ölçülebilir niteliktedir.

\section{BULGULAR}

\section{Sümerbank Kayseri Bez Fabrikası Mekânsal Özellikleri}

Yerleşke, içinde bulundurduğu yolları, depoları, yönetim binaları, hemen yakınında kurulan lojmanları, eğitim ve ibadet yerleri ve rekreasyon alanları ile bir endüstri kasabası niteliğindedir. Bu bağlamda fabrika yerleşkesi, çalışanlarını aileleri ile birlikte bir arada toplamayı amaçlayan mekânsal bir organizasyona sahiptir. Fabrika yalnızca bir üretim alanı olarak tek bir bina şeklinde değil bir yaşam kompleksi olarak tasarlanmış ve inşa edilmiştir (Şekil 1).

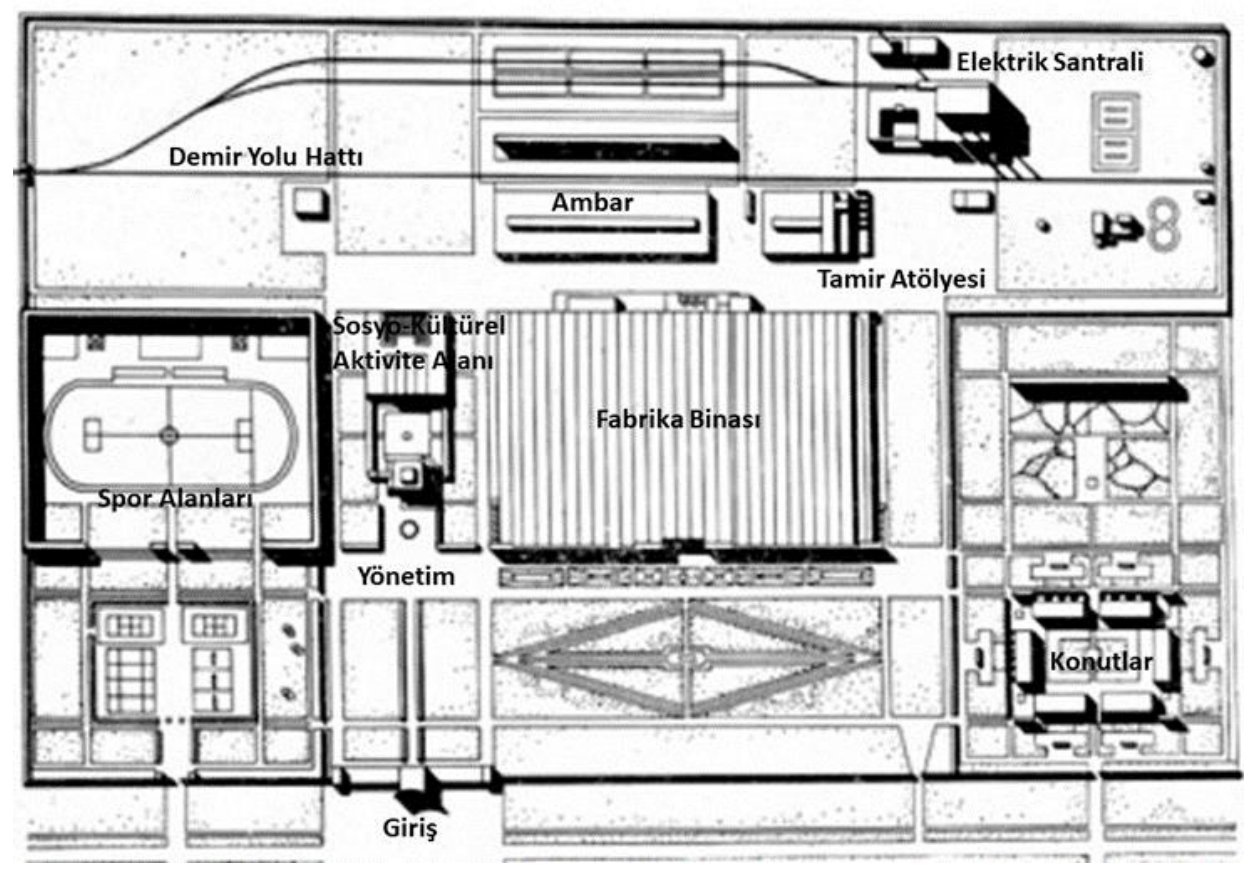

Şekil 1. Sümerbank Vaziyet Planı (Asiliskender ve Yöney 2015)

Dik açılı bir plan sistemiyle düzenlenen komplekste büyük taban alanlı yapılar, kuzey-güney doğrultusunda şeritler halinde yerleştirilmiş ve geniş yollarla birbirinden ayrılmıştır (Anonim 2019b).

Kuruluş yıllarında, 2100 iş̧̧i ile 155 memur çalıştıran fabrikanın; memur ve ustalar için konutları, revir, kreş, iş̧i ve memur lokali, market ve fırın gibi temel ihtiyaçları karşılayacak birimler ile sosyal amaçlı; sinema, 1000 kişilik kapalı tribünlü futbol sahası, tenis kortu gibi spor birimleri ve etrafında müzikli eğlencelerde düzenlenen yarı olimpik bir yüzme havuzu bulunmaktadır (Asiliskender ve Baturay Yöney 2018). İşletme binası, $144 \times 244$ m'lik genişlik ve yaklaşık $35.000 \mathrm{~m}^{2}$ 'lik kapalı alana sahiptir. Yerleşke, çok fonksiyonlu bir yerleşke olarak çalışanlarının sosyal, kültürel, eğitimsel ve ikamete yönelik gereksinimlerini karşılayan mikro ölçekli bir kent modeli ortaya koyan Kayseri'nin ilk ve tek yapılanmasıdır (Kevseroğlu 2011). Yerleşkede mevcut olan yapılar işlevleri ile birlikte Şekil 2 'de verilmiştir. 


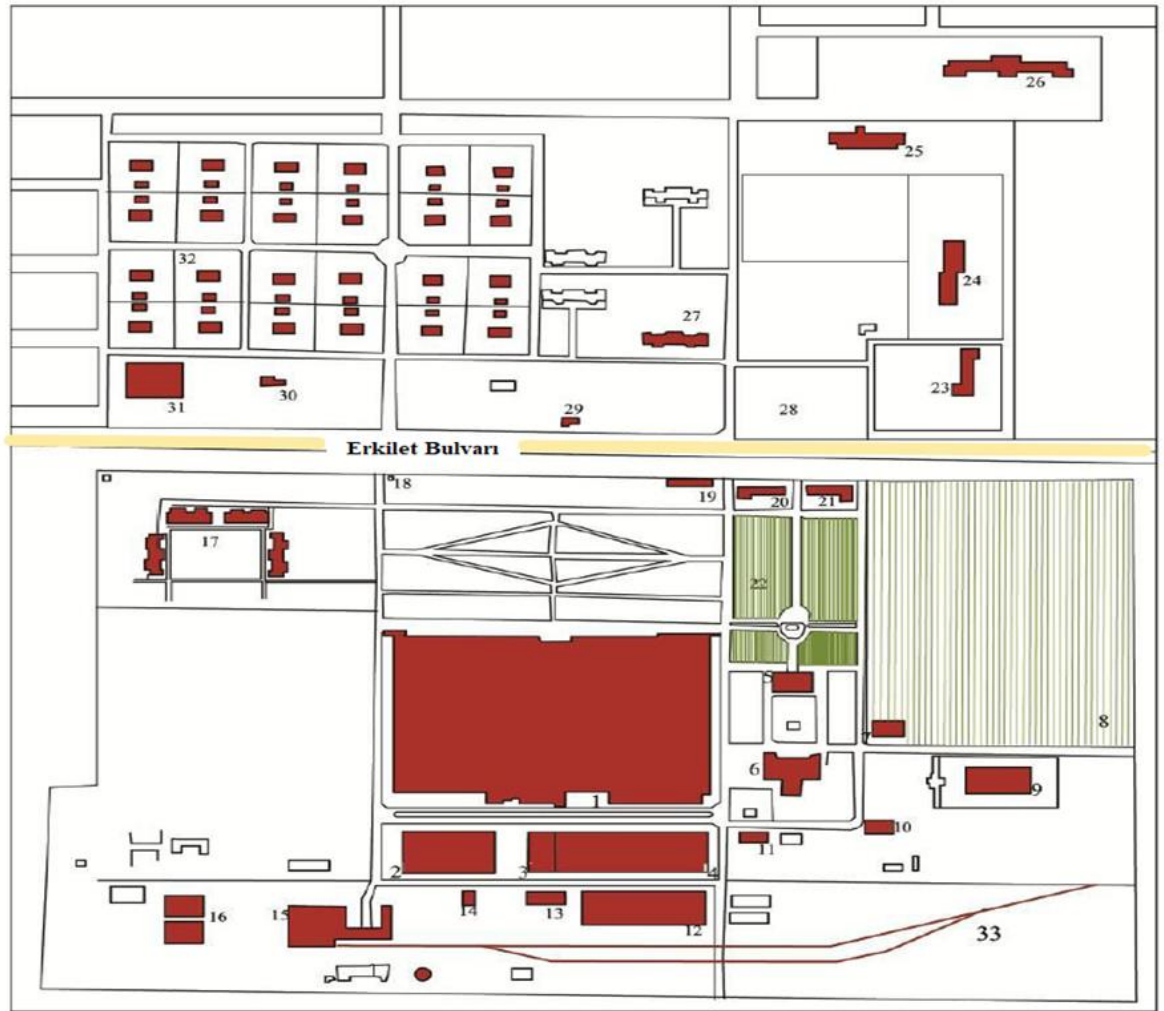

Şekil 2. Sümerbank Kayseri Bez Fabrikası Yerleşkesinde yer alan yapılar (Aslanoğlu 1979, Kevseroğlu 2011)

1) Fabrika Binası, 2) Atölye, 3) İşci Yemekhanesi, 4) Mamul Ambarı, 5) Müdüriyet Binası, 6) Sinema, 7) Misafirhane, 8) Stad, 9) Havuz, 10) Erzak Ambarı, 11) Ittfaiye ve Garaj, 12) Pamuk Ambarı, 13) Ambar, 14) Depo, 15) Santral, 16) Soğutma Havuzları, 17) Konutlar, 18) Bekçi Kulübesi, 19) İşç Lokali, 20) Savunma, 21) Poliklinik\& Kreş, 22) Çamlık Alan,23) Ilkokul, 24) Lise, 25) Orta Okul, 26) Bekâr Apartmanı, 27) Apartmanlar, 28) Cami, 29) Karakol, 30) Lojman, 31) Bölge Deposu 32) iş̧̧̧i Evleri, 33) Demir yolu hattı.

\section{Yerleşkenin Konumu ve Kentle ilişskisi}

Fabrika yerleşkesi kent merkezine yürünebilir mesafede olup yaklaşık 2 km uzaklıktadır. Kentin kuzey batısında yer alan çalışma alanına ulaşım İstasyon Caddesi ile sağlanmakta olup bölgeye birçok ulaşım güzergâhı bulunmaktadır. Alanın güneyinden doğu-batı yönünde uzanan demir yolu hattı geçmektedir (Şekil 3).

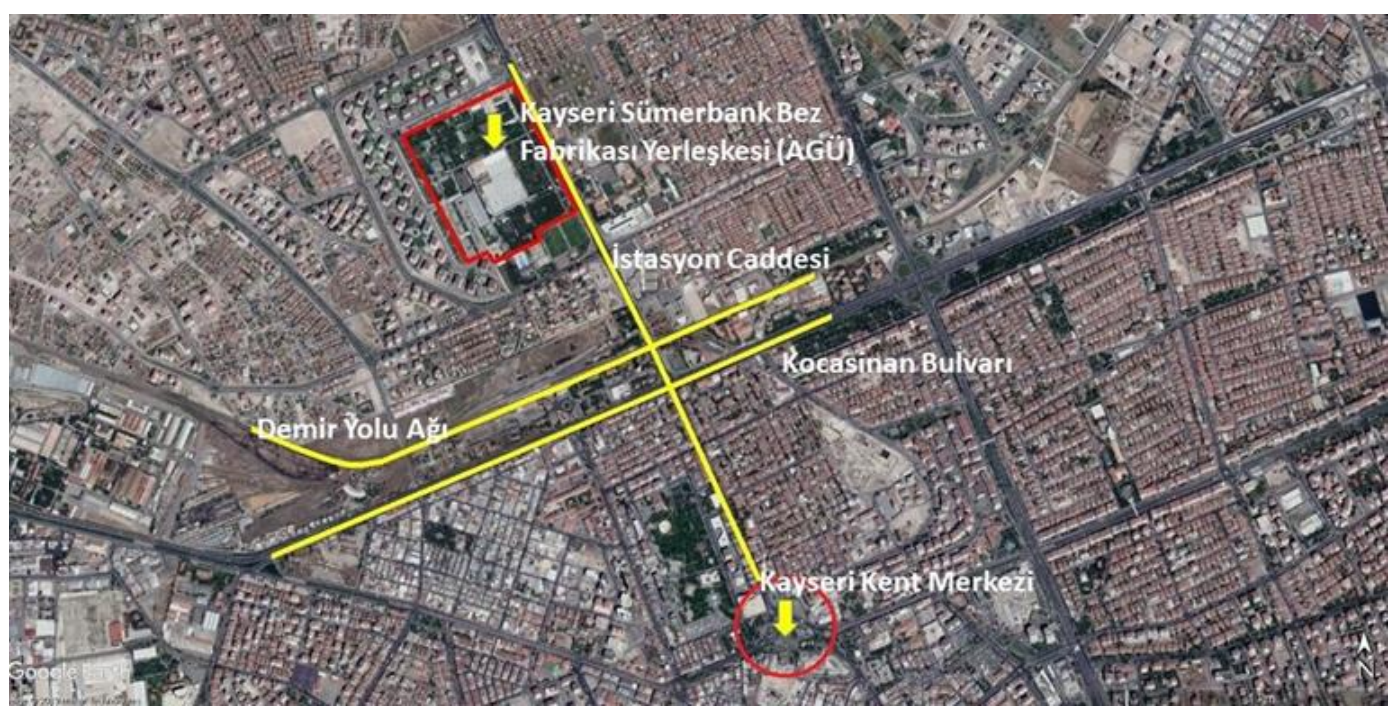

Şekil 3. Çalışma alanı konumu ve ana ulaşım aksları 
Sümer Bölgesi; Kayseri Emniyet Müdürlüğü, Kayseri Adalet Sarayı, Sümer Sosyal ve Spor Tesisleri gibi kamu alanlarının ve yüksek katlı yerleşim alanlarının bulunduğu bir çekim noktasıdır. Bu nedenle bölge hızlı bir şekilde yapılanmış, çok nüfuslu ve etkin bir bölgeye dönüşmüştür (Şekil 4).

Sümerbank kuruluşları Anadolu'nun birçok yerinde modern şehircilik anlayışını da beraberin de getirmiş, kentsel gelişimi etkilemiştir. Yerleşke çevresinde oluşan yeni yerleşim alanlarının kare ızgara plan (grid) sisteminde gelişmesi bunun en iyi göstergesidir (Kevseroğlu 2018). Çevresinde küçük ve az katlı binalar ile kütle yapıları da barındıran çalışma alanının, kent bütününde önemli bir büyüklüğe sahip açık-yeşil alan olması en belirgin niteliğidir.

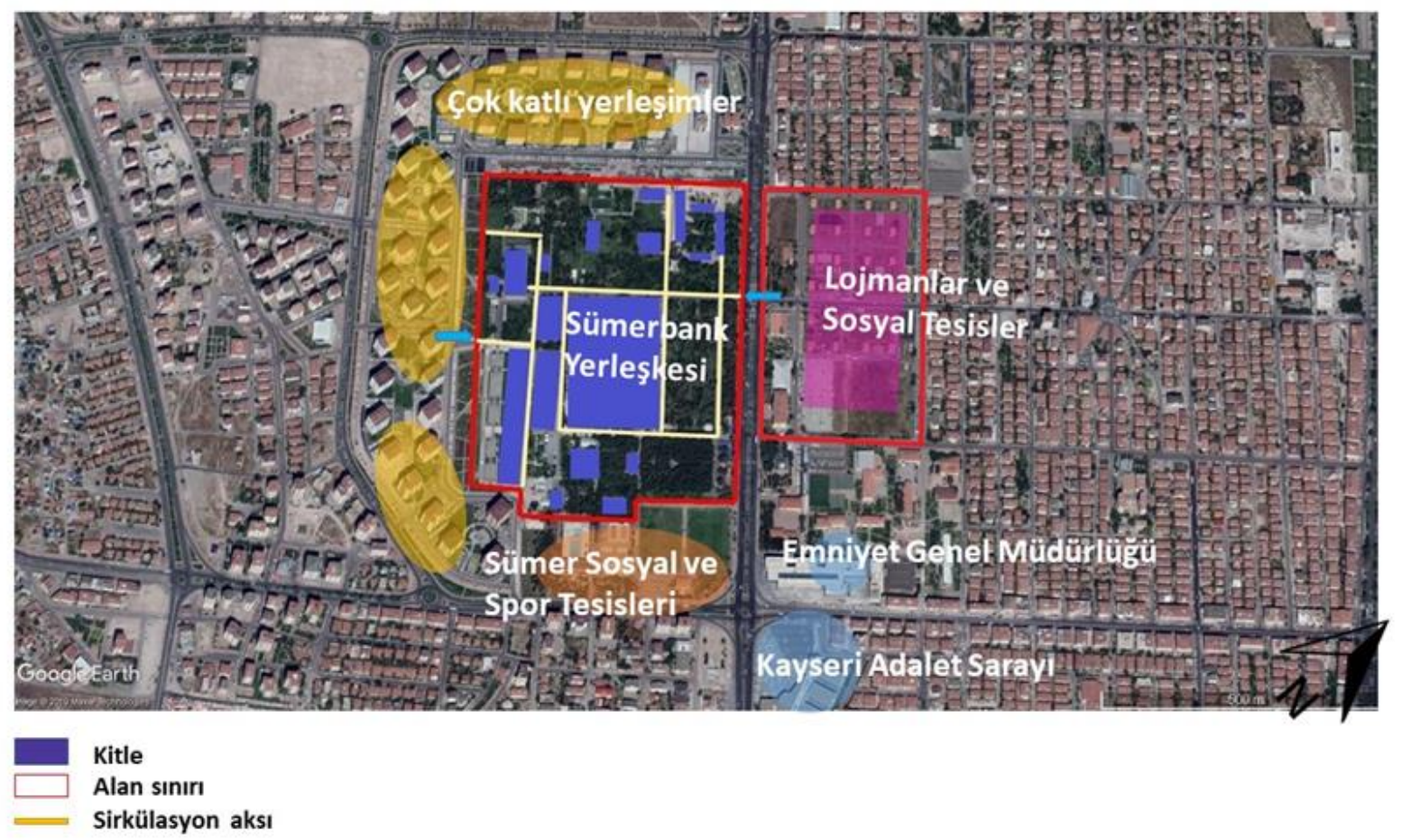

Şekil 4. Sümerbank Kayseri Bez Fabrikası Yerleşkesi yakın çevre analizi

\section{Sümerbank Kayseri Bez Fabrikası Yerleşkesi Günümüz Kullanımı: AGÜ Sümer Kampüsü}

Sümerbank Kayseri Bez Fabrikası Yerleşkesi, Erken Cumhuriyet Dönemi'nden günümüze kadar gelmiş endüstri miras alanı niteliğinde modern bir yaşam alanı kompleksidir. Hem kent kültüründeki hem de ulusal kimliğin oluşturulmasındaki öneminden dolayı yerleşke 2003 yılı sonunda "anıt" olarak tescillenmiş ve sit alanı olarak koruma altına alınmıştır (Asiliskender ve Baturay Yöney 2018).
49 yıllığına Abdullah Gül Üniversitesi'ne tahsis edilen Sümerbank Kayseri Bez Fabrikası Yerleşkesi 2012 yılının haziran ayında üniversiteye devir edilmiştir (Anonim 2019b). Yerleşke hem mimari hem de şehircilik açısından basit ve yalın nitelikler taşıyan binalardan oluşmaktadır (Asiliskender 2004). Yerleşkenin yeniden işlevlendirme çalışması AGÜ Mimarlık Fakültesi tarafından hazırlanan master planı çerçevesinde devam etmektedir (Şekil 5). 


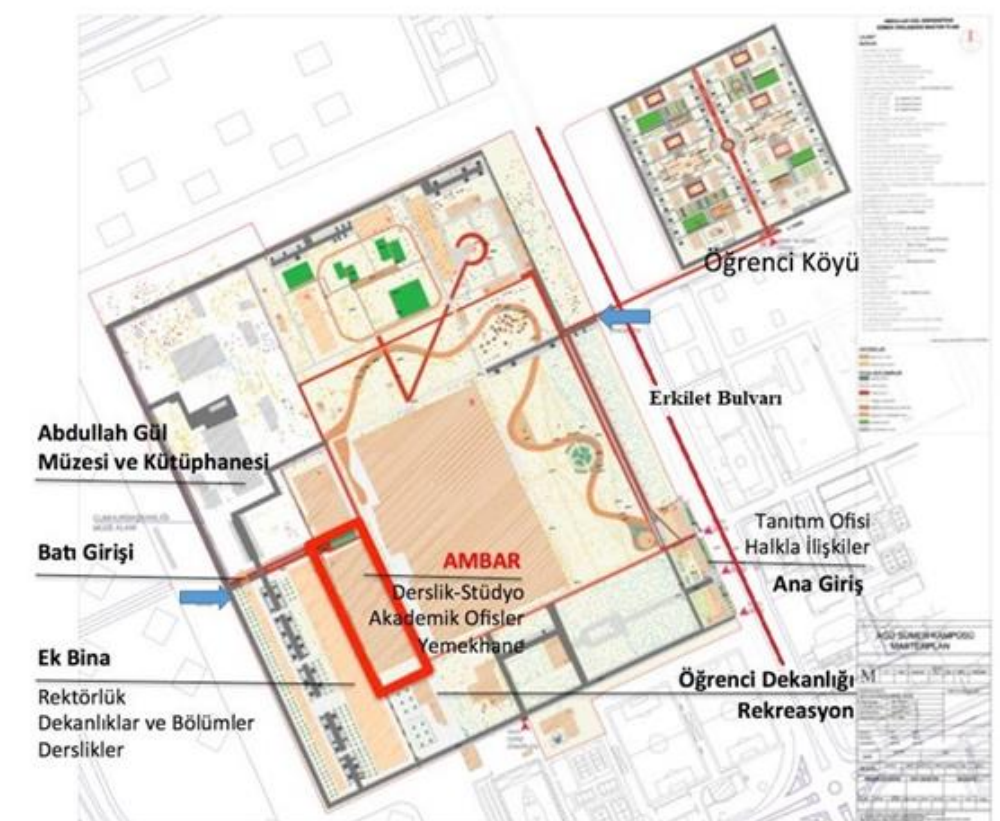

Şekil 5. Abdullah Gül Üniversitesi Sümer Kampüsü Master Planı (Anonim 2017)

Master Planı incelendiğinde yerleşke içindeki yapıların özgün değerlerinin korunarak yeniden işlevlendirildiği, açık alan düzenlemelerinin değiştirilmeden korunduğu ve üniversitenin ihtiyaçları doğrultusunda yeni kullanım alanlarının eklendiği görülmektedir. 180 bin $\mathrm{m}^{2}{ }^{\prime}$ lik bir yeşil alana sahip olan yerleşkede eğitim ve öğretime ayrılan birimler yerleşkenin doğu girişinden kuzeybatı yönüne doğru öğrenci köyü, açık-kapalı spor alanları, restoran ve kafe, müze, sergi salonu ve ziyaretçi merkezi ile desteklenmiştir.
Yerleşkeye giriş iki adet doğu yönünde bir adet batı yönünde olmak üzere üç ana kapıdan sağlanmaktadır. Doğu girişi geniş ve düz bir şekilde T.C. Cumhurbaşkanlığı Abdullah Gül Müze ve Kütüphane binasına ulaşmaktadır. Yol boyunca Picea orientalis, Cedrus libani ve Pinus nigra bitkileri kullanılarak alle tipi bitkilendirme yapılmış, mekâna derinlik kazandırımış ve yayalar yürümeye teşvik edilmiştir (Şekil 6).

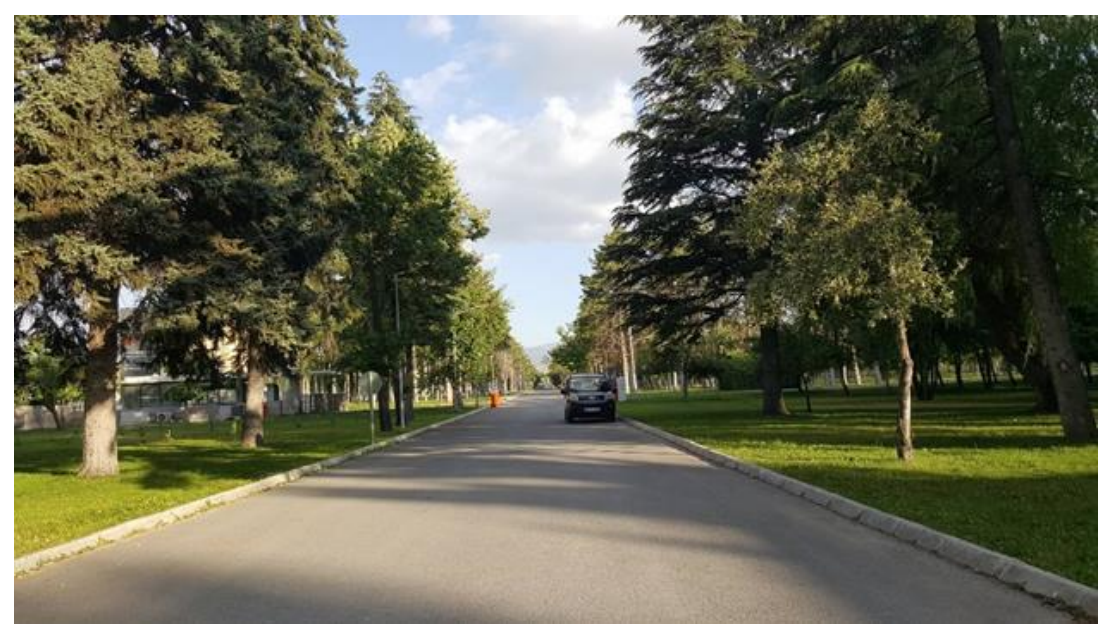

Şekil 6. Yerleşkenin doğu girişi

Batı girişi ise yine düz bir şekilde derslik, akademik ofisler ve yemekhanenin bulunduğu eski ambar binasına ulaşmaktadır. Kullanıcı yoğunluğu sebebiyle girişte geniş bir otopark alanı tasarlanmıştır. Girişin sol tarafı kullanılan geometrik su yüzeyi ile desteklenerek alandaki yoğun sert zemin etkisi kırımıştır. Otopark alanında Gleditsia 
triacanthos, Cedrus libani ve Cedrus atlantica 'Glauca' bitkileri kullanılarak gölgelik alanlar oluşturulmuştur. Girişin sağ tarafında T.C. Cumhurbaşkanlığı Abdullah Gül Müze ve Kütüphane binasına ulaşan bir aks bulunmaktadır. Bu aksta bulunan mevcut türler korunmuş, Ginkgo biloba, Acer platonoides 'Crimsonking', Liquidambar orientalis, Berberis thunbergii, Nandina domestica, Rosa sp. gibi bitki türleri ile desteklenen bir yürüyüş yolu kurgulanmıştır (Şekil 7).
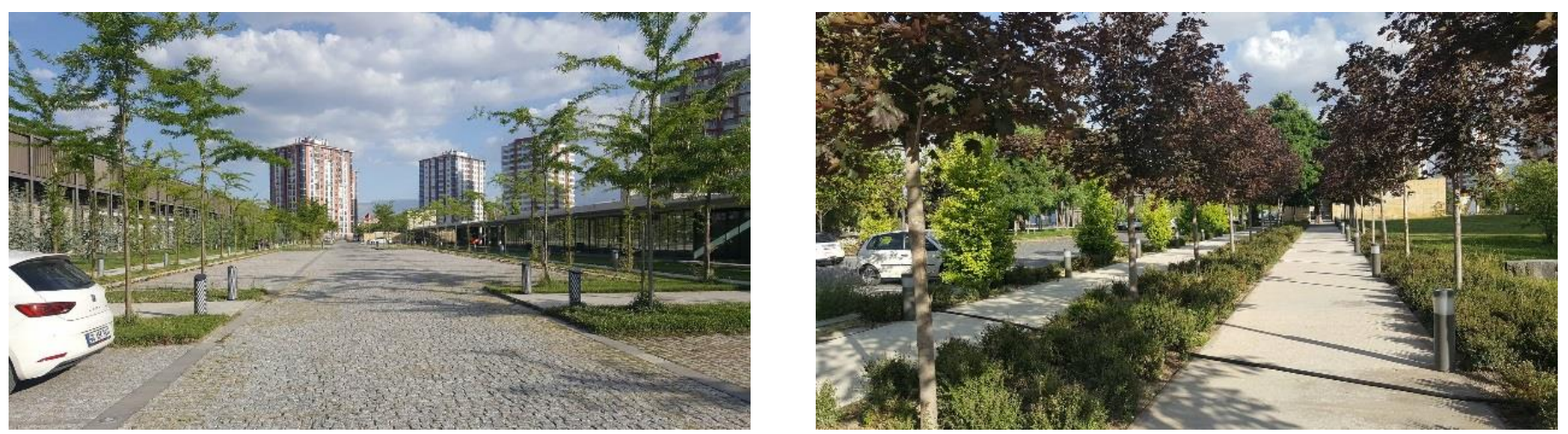

Şekil 7. Yerleşkenin batı girişi

Kampüsün kuzeybatısında 2 adet soğutma havuzu bulunmaktadır. Bu havuzların mevcut sütunları korunarak biri ahşap basamakların kullanılarak inildiği çim yüzeye ulaşan bir amfi olarak, diğer de yine ahşap basamakların

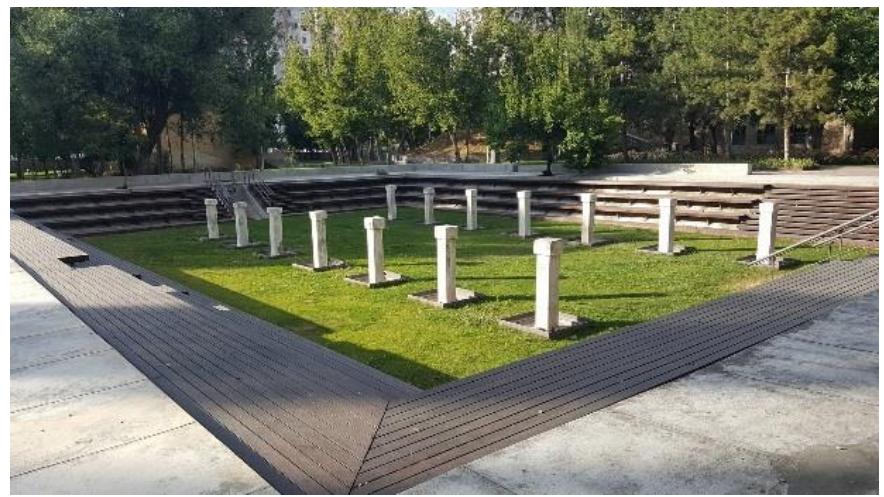

kullanılarak inildiği, üzerinde formal adım taşları ile yürünebilen ve Mentha sp., Thymus sp., Carex sp. gibi sucul bitkilerle desteklenenmiş bir amfi olarak düzenlenmiştir (Şekil 8).

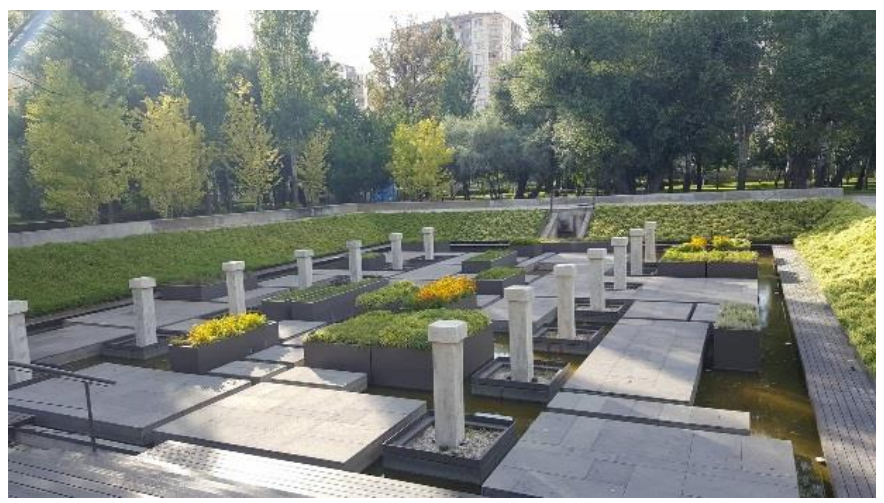

Şekil 8. Soğutma havuzlarından yapılan amfiler

Kampüsün kuzeydoğusunda bulunan eski lojman binaları yine öğrenci köyü konsepti ile tekrar barınma amaçlı kullanıma sunulmuştur. Öğrenci köyünün çevresinde açık ve kapalı spor alanları (tenis kortları, basketbol, futbol ve voleybol sahaları, fitness salonu) ve rekreatif ihtiyaçları karşılayan nitelikli açık-yeşil alanlar bulunmaktadır.

Illk restorasyon giriş yapıları ile yerleşkenin güneyinde bulunan ambar binası, elektrik santrali, itfaiye ve büro binalarında gerçekleştirilmiştir. Ambar binası; derslik, akademik ofisler, kafe, yemekhane ve öğrenci yaşam ve çalışma alanları gibi kullanımları içeren bir yapıya dönüştürülmüştür. Yerleşkenin kuzeyinde bulunan santral binaları yapılan restorasyon ile T.C. Cumhurbaşkanlığı Abdullah Gül Müze ve Kütüphanesi'ne dönüştürülmüş ve yeniden işlevlendirilmiştir. Yerleşkenin doğu girişinde bulunan üç ayrı yapı üniversite tanıtım ofisi, idari ofisler, toplantı salonları, sergi alanları, kafe ve market olarak düzenlenmiştir.

Yerleşkenin kuzeydoğusunda bulunan işçi evleri ve konutlar yine lojaman ve öğrenci köyü olarak değerlendirilmiş, çevresi açık-kapalı rekreatif faaliyet alanı olarak değerlendirilmiştir (Şekil 9). 

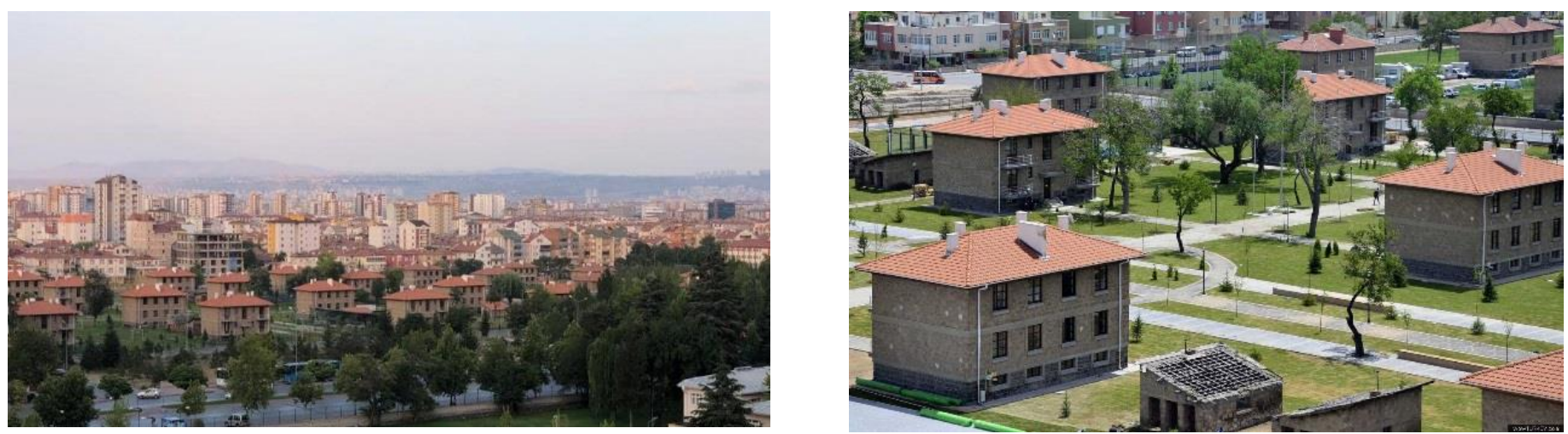

Şekil 9. AGÜ öğrenci köyü

Yerleşke, kapalı ve açık-yeşil alanları ile kentsel peyzaja entegre olmuş kentlinin de aktif olarak kullanabildiği bir alan durumundadır. Çalışma alanındaki peyzaj gelişimini ve kentsel peyzaj arasındaki ilişkiyi değerlendirebilmek için Loures ve ark. (2008)'in endüstriyel alanların tasarımı konusunda belirlediği çizelge çerçevesinde yapılan yeniden işlevlendirme çalışmasını incelemek bu bağlamda bu alan için genel bir veri oluşturmada yardımcı olacaktır.
Çizelgedeki tasarım kriterleri, terk edilen endüstriyel peyzaj alanlarının yeniden kentle bütünleşmesi açısından algılanabilir ve ölçülebilir kalite ölçütü niteliğindedir. Aktivite kullanımlar, ulaşılabilirlik, konfor ve imaj, sosyallik ve endüstriyel kimlik ana hedeflerinin alt kriterleri gibidirler. Alan genelinde tüm bu kriterlerin olması beklenmemektedir (Çizelge 1).

Çizelge 1. Sümerbank Kayseri Bez Fabrikası Yerleşkesinin (AGÜ Sümer Kampüsü) Endüstriyel Miras Alanlarında Peyzaj Tasarımında Dikkate Alınması Gereken Tasarım Kriterleri Doğrultusunda Değerlendirilmesi (Loures ve ark. 2008)

\begin{tabular}{|c|c|c|}
\hline Tasarım Kriterleri & Var/Yok & Peyzaj Tasarımı Değerlendirmesi / Önerisi \\
\hline Açıklık ve Kimlik & $\checkmark$ & $\begin{array}{l}\text { Yerleşkenin genel yapısı (yapısal ve bitkisel) korunmuş olup endüstriyel miras alanı vurgusu } \\
\text { "Fabrikadan Üniversite Kampüsüne" sloganı ile fark edilebilir nitelikte kamusal kullanıma } \\
\text { açılmıştır. }\end{array}$ \\
\hline $\begin{array}{l}\text { Alanın Çevresiyle Kurduğu } \\
\text { Bağlantı }\end{array}$ & $\checkmark$ & $\begin{array}{l}\text { Yerleşke yakın çevresi ve kent bütünü ile tarihi, kültürel, eğitim, rekreatif olmak üzere işlevsel ve } \\
\text { alan kullanımları arasında estetik bir bağlantı oluşturmaktadır. }\end{array}$ \\
\hline Aktivitelerdeki Yoğunluk & & $\begin{array}{l}\text { Yerleşke içindeki yapılar ve açık alanlar kullanım ihtiyacına göre (üniversite yerleşkesi) şekillenmiş } \\
\text { olup fazla yoğunluk bulundurmamaktadır. }\end{array}$ \\
\hline Bütüncül Tasarım & $\checkmark$ & Alan genelinde planlanan/tasarlanan alan kullanımları birbirleri ile uyum içerisindedir. \\
\hline Çekicilik & $\checkmark$ & $\begin{array}{l}\text { Farklı mimari kurgusu ile alan dikkat çekicidir. Yeniden işlev kazandırılan ve restore edilen yapıları, } \\
\text { peyzaj tasarımı ile açık-yeşil alanlar hem estetik ve hem de fonksiyonellik açısından çekici hale } \\
\text { getirilmiştir. }\end{array}$ \\
\hline Çevresel Eğitim ve Yatırım & & $\begin{array}{l}\text { Halk endüstriyel miras ve endüstriyel peyzaj alanları hakkında bilgilendirilmeli ve halkın katılımı } \\
\text { sağlanmalıdır. }\end{array}$ \\
\hline Denge ve Sinerji & $\checkmark$ & Yeniden işlevlendirme çalışmasında kitle boşluk dengesine önem verilmiştir. \\
\hline Dinamik Oluşumlar & & $\begin{array}{l}\text { Yerleşkenin güneyinde bulunan demir yolu hattı tesislerin farklı kullanımına imkân sunabilecek } \\
\text { potansiyel oluşturabilir. }\end{array}$ \\
\hline Endüstri Mirası & $\checkmark$ & $\begin{array}{l}\text { Endüstri mirası olan tüm yapılar daha fazla tahrip edilmeden planlama kararları alınmış, endüstri } \\
\text { mirası alanın yapısal ve mekânsal ölçüde temsil edilmesi ilk hedef olmuştur. }\end{array}$ \\
\hline Erişilebilirlik & $\checkmark$ & Araç ve yaya erişimi için doğu ve batı girişleri bitkisel ve yapısal tasarımlar ile desteklenmiştir. \\
\hline Esneklik & & $\begin{array}{l}\text { Yerleşkedeki açık alanlar farklı amaçlar için kullanıma uygundur (açık hava etkinlikleri, sergi, } \\
\text { atölye çalışması vb. gibi). }\end{array}$ \\
\hline Eşsizlik ve Kültürel Değerler & $\checkmark$ & Yerleşke içinde bulunan yapılar eşsiz kültürel değerlerdir. \\
\hline Finansal Kapasite & $\checkmark$ & $\begin{array}{l}\text { Şu anki alan kullanımı vakıf üniversitesine devredilmiş olması sebebiyle finansal destek sorunu } \\
\text { yaşanmamaktadır. }\end{array}$ \\
\hline Fonksiyonellik ve Yoğunluk & $\checkmark$ & $\begin{array}{l}\text { Yerleşke genelinde monotonluktan uzak, kullanım amacına uygun, endüstriyel miras değerini } \\
\text { yansıtan kamusal alanlar kullanımları kurgulanmıştır. }\end{array}$ \\
\hline Görsel ve İşlevsel Süreklilik & $\checkmark$ & $\begin{array}{l}\text { Alan içindeki açık-yeşil alanlar ve yapılar görsel açıdan kullanıcılara hitap etmekte, yüklenilen } \\
\text { fonksiyonlar süreklilik arz etmektedir. }\end{array}$ \\
\hline
\end{tabular}


Çizelge 1 (Devamı). Sümerbank Kayseri Bez Fabrikası Yerleşkesinin (AGÜ Sümer Kampüsü) Endüstriyel Miras Alanlarında Peyzaj Tasarımında Dikkate Alınması Gereken Tasarım Kriterleri Doğrultusunda Değerlendirilmesi (Loures ve ark. 2008)

Güvenlik

Halkın Katılımı ve Payda Katılım Hareket Kolaylı̆̆ı

Kaliteli Tasarım

Karakter ve Bağlam

Kaynakların Verimli Kullanımı

Nirengi Noktaları (Landmarks)

Okunabilirlik

Ortaklık

Rahatlık

Sürdürülebilirlik

Tarafsızık

Tasarım ile Bölgede Değişim Yaratmak

Ulaşım Ağı

Uyum ve Esneklik

Uyumluluk

Yayaların Alana Rahat Erişimi ve Alan içinde Rahat Hareket Edebilmeleri

Yeniden Kullanım

Yenilik ve Yaratıcılık

Ziyaretçiler için Tasarlanan Kamusal Mekânlar

Hareket Kolaylığı
Giriş noktalarında güvenlik bulunmaktadır. Ancak alanda kullanılan aydınlatma sistemleri yetersizdir. Yapılacak yeterli aydınlatma tasarımı ile alan gece de kullanıcıların kendilerini güvende hissedebilecekleri kamusal mekâna dönüştürülmelidir.

Alan için ön görülen planlama (koruma-kullanma) kararlarında halkın katılımı sağlanmalıdır.

$\checkmark \quad$ Yeni master planı kapsamında alanın eski ulaşım aksları korunmuştur. İyileştirilen ana ve ara akslar yoğun kullanıma izin verecek niteliktedir.

$\checkmark \quad$ Yapısal ve sert zemin peyzaj tasarımı ile bitkisel tasarım için bölge iklim şartlarına uygun malzeme ve bitki türü seçimi yapılmıştır.

Giriş, ulaşım sirkülasyonu, toplanma-dağılma alanları, düğüm noktalarında alanın sahip olduğu endüstri mirası karakteri daha güçlü hissettirilmelidir.

$\checkmark \quad$ Tarihi değer ve endüstri mirası değeri taşıyan yapılar kültür ve eğitim amaçlı yapılara dönüştürülmüştür. Mevcut bitki örtüsü korunarak yeni bitkilendirme tasarımı ile tekrar yorumlanmıştır.

$\checkmark \quad$ Alan içindeki, Abdullah Gül Müzesi ve Kütüphanesi ile Ambar binası (derslik ve akademisyen ofisleri binası) nirengi noktası niteliğindedir.

$\checkmark \quad$ Yerleşke içindeki yapıların çoğu yapı koruma altında olduğu için yapıların konumları değiştirilmeden kullanıcıların alanı kolay bir şekilde okuyabilecekleri ulaşım sirkülasyonu kurgulanmıştır. Alternatif yürüyüş yolları ile yerleşke içindeki mekânlar birbirine bağlanmıştır. Alanın okunabilirliği mevcut mimarisi ile çevresindeki yapılardan ayrılarak var olmaktadır.

$\checkmark \quad$ Yerleşkenin dönüşümü kamu- vakıf (özel) ortaklığında yürütülmektedir.

$\checkmark \quad$ Yerleşke kullanıcıların rahat ulaşabileceği ve kullanabileceği okunabilir, güvenli ve erişilebilir durumdadır.

$\checkmark \quad$ Yerleşkede değişen alan kullanımları ile birlikte mevcut yapılar korunarak yeniden işlevlendirilmiştir. Ayrıca bitkisel anlamda alandaki mevcut bitki örtüsü de korunmuş, alan kullanımlarının sürdürülebilirliği yapılan bitkilendirme ve ek yapısal ve sert zemin tasarımları ile desteklenmiştir.

$\checkmark \quad$ Alan içindeki açık-yeşil alanlar kamu hizmeti vererek kamusal açık alan işlevini üstlenmektedir.

$\checkmark \quad$ Daha önce tehlike ve güvensizlik teşkil eden, atıl durumdaki endüstriyel peyzaj alanı eğitim, kültür, sanat vb. aktivitelere ev sahipliği yapan kamusal alana dönüşmesi ile bölgenin sosyokültürel yapısı değişmiştir.

$\checkmark \quad$ Erkilet Bulvarı ile karayolları ana ulaşım bağlantısı iken Oymak Caddesi ile alternatif ulaşım sağlanmaktadır.

$\checkmark \quad$ Alana kazandırılan yeni işlevler birbiriyle ve alanın kimliğiyle uyumludur. Ayrıca bu kullanımların dışında farklı kullanımlara da cevap verecek esnekliktedir.

$\checkmark \quad$ Yerleşkede bulunan mevcut yapılar mimari karakteristikleri açısından uyum içindendir. İhtiyaç doğrultusunda inşa edilen ve işlev kazandırılan yapılar bu karakteristik mimari bütünlük ile uyum sağlamaktadır.

$\checkmark \quad$ Alan içi ve yakın çevresi ile etkin bir bağlantı sağlanmış olup yayalar alan içinde rahat ve güvenli bir şekilde hareket edebilmektedirler.

$\checkmark \quad$ Yapıların farklı işlevler ile yeni mekânlara dönüştürülmüştür. Ayrıca yerleşke içinde bulunan yapılara ait makineler, objeler vb. ögeler alanın varlığını vurgulayıcı donatı elemanı olarak kullanılabilir.

$\checkmark \quad$ Mevcut yapıların yeni mimari fikirler ile değerlendirilmeleri alan içinde her türlü yaratııı fikrin uygulanabilirliğine olanak sağlamaktadır.

$\checkmark \quad$ Alanın geniş açık-yeşil alanlara sahip olması kent içinde kamusal açık-yeşil alan olarak değerlendirilmesine olanak vermektedir.

$\checkmark \quad$ Alan içinde kurgulanan mekânlar ve mekânlar arası bağlantı ilişkisi yayalara hareket kolaylığı sağlamakta olup yoğun kullanıma izin verecek genişliktedir.

\section{Tartışma ve Sonuç}

Doğal, kültürel, sosyal ve tarihi öğelerin oluşturduğu birikim her kente farklı bir kimlik kazandırmaktadır. Ancak kentlerin kimlikleri üzerinde sadece doğal koşullar etkili değildir. Sosyo-kültürel peyzaj öğeleri de kentlerin kendilerine özgü kimliklerini kazanmalarına katkı sağlamaktadır (Köylü ve Kiper 2007). Kente kimlik kazandıran, onu geçmiş ile bir arada tutan, kent belleğinin saklı kalmasına büyük katkı sağlayan en büyük 
parametrelerden birisi de yapılardır. Bu anlamda konut bölgeleri dışında en önemli yapı birimlerini endüstri yapıları oluşturmaktadır (Sertaç ve ark. 2015).

Endüstriyel miras alanları küreselleşme ile birlikte kullanılmadıkları için kent içerisinde atıl durumda kalmış, çöküntü bölgelerine dönüşmüşlerdir. Son yıllarda üretimi sona ermiş endüstriyel peyzaj alanları yapılan yeniden işlevlendirme çalışmaları ile kentsel peyzaja entegre edilmeye başlanmıştır. Sanayi sonrası endüstriyel miras alanları, kentsel peyzaja entegre edildiklerinde farklı düzeylerde topluma değerli bir kaynak teşkil etmekte, kentsel peyzaj değerini ve yaşam kalitesini arttırmaya katkıda bulunmaktadır (Loures ve ark. 2008). Bu bağlamda Loures ve ark. (2008 ve 2011) uluslararası düzeyde yeniden işlevlendirilmiş 6 farklı endüstriyel peyzaj alanını geliştirdikleri kriterler çerçevesinde ele almış, bu alanlarda rahatlık, tasarım ve değişim, tarafsızlık, kaliteli tasarım, güvenlik, fonksiyonellik ve yoğunluk, kaynakların verimli kullanımı kriterlerinin sağlanamadığını tespit etmişlerdir. Yine aynı şekilde Tabak (2011) yaptığı çalışmada Yedikule Gazhanesi endüstriyel peyzaj alanını bu kriterler çerçevesinde değerlendirmiş; çekicilik, endüstri mirası, eşsiz ve kültürel değerler, nirengi noktaları, ulaşım ağı ve uyumluluk ilkelerinin alan genelinde var olduğunu tespit etmiştir. Bu bağlamda endüstriyel peyzaj alanlarına yönelik geliştirilen tasarım ve planlama ilkeleri çalışma alanı için uyarlanmış, kriterler tabloda mevcut olup olmama durumuna göre ele alınmış ve mevcut olan kriterler değerlendirilerek olmayanlara geliştirici öneriler getirilmiştir. Çalışma alanı genelinde aktivitelerdeki yoğunluk, karakter ve bağlam, halkın katılımı ve payda katılım, dinamik oluşumlar, esneklik, çevresel eğitim ve yatırım ilkelerinin yapılan yeniden işlevlendirme çalışmasında sağlanamadığı tespit edilmiştir. Bu noktada geliştirilen bu tasarım ve planlama ilkelerinin yeniden işlevlendirme çalışmalarında baz alınması ve uygulanması projelerin başarısına temel oluşturmamaktadır, ancak bu kriterlerin yol gösterici olacağı düşünülmelidir.

İşlevini yitirmiş bir endüstriyel alanın dönüşümünde anıtsal ve ticari olmak üzere iki tür yaklaşım söz konusudur. Anıtsal yaklaşımda endüstriyel tesis mümkün olduğunca özgün işlevini sürdürmekte, işler hale getirilmekte ve üretim değil sergileme ve eğitim amaçlamaktadır. Ticari yaklaşımda ise tesisin çevre ile etkileşimi doğrultusunda en uygun işlev belirlenerek tesise özgün işlevinin dışında yeni işlevler kazandırımaktadır (Kıraç 2001). Bu bağlamda çalışma alanına ticari yaklaşımın dışında üniversite yerleşkesi olarak yeni bir işlev kazandırılmıştır. Böylelikle alan, hem eski kullanımın ardından yeni bir kullanıma sahip olmuş, hem de kentin tarihinde izler bırakan endüstriyel miras olarak çöküntü alan olmaktan kurtulmuştur. Ayrıca bulunduğu çevrenin kimliği şekillendirilmiş ve yerleşke kent için bir imge (landmark) olmuştur.

Ülkemizde işlevini yitirmiş birçok endüstriyel peyzaj alanlarının kentsel peyzaja entegre çalışmaları yapılmış ve yapılmaktadır. Ancak bu dönüşüm projeleri noktasal restorasyon projeleri şeklinde gelişmekte bütüncül yaklaşım stratejisi doğrultusunda ele alınmamaktadır (Kariptaş ve ark. 2015). Yeni işlevler mimari, teknolojik ve maddi özelliklerin korunması yoluyla fiziksel bina stokunun tekrar kullanılmasının ötesine geçmeli ve yen bir ekonomik, sosyal, kültürel ve tarihi ruh yaratmalıdır (Henket 2015, Asiliskender ve Yöney 2016). Bu bağlamda çalışma alanının kentsel peyzaja entegre çalışması daha bütüncül yaklaşımla ele alınmış, endüstriyel miras ögeleri çevreleri ile birlikte değerlendirilmiştir. Yerleşkenin sahip olduğu açık-yeşil alanlar korunmuş ve iyileştirilmiştir. Böylece alanın, hem kent açık-yeşil alan miktarına hem de kentlinin ihtiyacı olan açık-yeşil alan sistemine katkısı bulunmaktadır.

Günümüzde sürdürülebilirlik birçok alanda olduğu gibi endüstriyel miraslarında sürekliliğinin sağlanmasında kilit bir kavram haline gelmiştir. Kayseri gibi sanayi kentlerinde kent merkezi içinde kalan, işlevini yitirmiş ve Sümerbank Kayseri Bez Fabrikası gibi tarihi önemi bulunan fabrika ve fabrika yerleşkelerinin endüstriyel peyzaj çerçevesinde kentsel peyzaja yeniden kazandırılması kapsamında Abdullah Gül Üniversitesi Sümer Yerleşkesi kullanımı ile yeniden kullanıma açılması kültürel sürdürülebilirlik adına önemli bir uygulamadır. Halkın, üniversitenin, yerelmerkezi kurum ve kuruluşların ortak çalışmasının bir sonucu olan fabrika yerleşkesinin bir üniversite yerleşkesi olarak yeniden işlevlendirilmesi ülkemizde endüstriyel peyzaj kavramının anlaşılmasına ve endüstriyel peyzaj alanlarına bakış açısının değişmesine olumlu bir adım olarak düşünülmelidir. Sonuç olarak tarihi ve ekonomik olarak önemi bulunan endüstriyel peyzaj alanları birer alternatif kültür bölgesi olarak düşünülmeli ve doğru şekilde yeniden işlevlendirilerek kentsel peyzaj kazandırılan örnekler çoğaltılmalıdır.

\section{KAYNAKLAR}

Anonim (1991) Tanıtım Broşürü, Sümer Holding A.Ş. Kayseri Pamuklu Sanayi İşletmesi. Kayseri Büyükşehir Belediyesi, Sümerbank Kayseri Bez Fabrikası Doküman Arşivi, 2009. 
Anonim (2017) http://www.arkitera.com/gorus/996/fabrikadanuniversite-kampusune--agu-sumer-kampusu1 (31.07.2019)

Anonim(2019a) http://www.cabernet.org.uk/index.asp?c=1134>, (04, 07, 2019)

Anonim (2019b) http://arch.agu.edu.tr/tarihce, (17.12.2019)

Anonymous (2003) (TICCIH-2003). The Nizhnytagil Charter for the Industrial Heritage, http://ticcih.org/ (12.09.2019)

Asiliskender B (2004) Erken Cumhuriyet'in 'Modern' Mirası: Sümerbank Kayseri Bez Fabrikası ve Lojmanları. Mimarlık Dergisi, S:316

Asiliskender B (2008) Modernleşme ve Konut: Cumhuriyet'in Sanayi Yatırımları ile Kayseri'de Mekânsal ve Toplumsal Değişim. Doktora Tezi, İstanbul Teknik Üniversitesi, Fen Bilimleri Enstitüsü, İstanbul

Asiliskender B, Baturayoğlu Yöney N, (2018) Fabrikadan Üniversite Kampüsüne: AGÜ Sümer Kampüsü. Süper Kent Kayseri TBMMO Kayseri Şubesi Yayını

Asiliskender B, Yöney N, (2016) The Revolarization of Industrial Heritage: AGU Sümer Campus in Kayseri, Turkey. World Herıtage and Degradation Smart Design, Planning and Technologies Le Vie dei Mercanti XIV Forum Internazionale di Studi, Napoli/Capri

Aslanaoğlu NG, (1979) Erken Cumhuriyet Dönemi Mimarlığı (Sosyal, Ekonomik,

Kültürel, Ortam Değişimi ve Mimarlığa Yansıması. ITÜ Mimarlık

Fakültesi, Doktora Tezi, ìstanbul.

Cossons N (1993) The BP Book of Industrial Archeology, London.

Dağ H, Özberk S (2012) Eski Sanayi Kentlerinde Kentsel Dönüşünden Kültürel Dönüşüme; Ruhr Bölgesi Örneği. KSÜ Sosyal Bilimler Dergisi, Cilt 9 Sayı 2. S.148-166.

Föhl A (1995) Bauten der Industrie and Tecknik, Schriftenreihe des Deutschen Nationalkomitees für Denkmalsschutz, 47, Bonn.

Görgülü Z (2009) Sürdürebilirlik, Planlama ve Politikalar, Uluslararası Mimarlık ve Planlama Sempozyumu, Bildiri Kitabı.

Henket HJ (2015) "The Oppressive New and the Vulnerable Old Meet; a Plea for Sustainable Modernity", DOCOMOMO Journal 52, Lisbon, p. 14-19.

Kariptaş Seçer F (2010) Endüstri Mirasının Yeniden Değerlendirilemesi. Yapı Dergisi 346 Eylül, 2010

Kariptaş Seçer F, Altuncu D (2009) "Re-Evaluation Of Industrial Buildings Within The Scope Of Industrial Archeology Under Present-Day Conditions " LIVENARCH IV "(RE/DE) Construction in Architecture", Karadeniz Teknik Üniversitesi, Trabzon
Kariptaş Seçer F, Erdinç J, Diçer B (2015) Endüstriyel Mirasın Kentlerdeki Kültürel Sürdürülebilirlik Bağlamında İncelenmesi. 2nd International Sustainable Building Symposium, s:512-516

Kaya S, Yerli Ö, Döner S (2015) Endüstriyel Alanların Endüstriyel Parklara Dönüşümü. Düzce Üniversitesi Bilim ve Teknoloji Dergisi, Sayı:3, s:518-534

Kıraç AB (2001) Türkiye'deki Tarihi Sanayi Yapılarının Günümüz Koşullarına Göre Yeniden Değerlendirilmeleri Konusunda Bir Yöntem Araştırması. Doktora Tezi, Mimar Sinan Üniversitesi, Fen Bilimleri Enstitüsü, İstanbul.

Kirkwood NG, Hollander JB, Gold JL (2010) Principles of Brownfield Regeneration; Cleanup, Design, and Reuse of Derelict Land, 2010, Island Press, Washington.

Koçan N (2011) "Sanayi Alanlarının Dönüşümü: Uşak Eski Tabakhane Deri Sanayi Bölgesi", Karadeniz Fen Bilimleri Dergisi, Cilt 1, Sayı 3, S. 124-138.

Köylü P, Kiper TD (2007) Kent Kimliğini Oluşturan Değerler ve Kimliksizleşme Üzerine

Örneklemeler, TMMOB PMO Peyzaj Mimarlığı Kongresi 3. Kongresi, Antalya-Türkiye.

Loures L, Burley J, Panagopoulos T (2011) Postindustrial Landscape Redevelopment:

addressing the past, envisioning the future. Internatıonal Journal of Energy And Environment, v:5, p: 714-724

Loures L, Panagopoulos T, Burley J (2008) Postindustrial Land TransformatioN:From Theory to Practice and Vice-Versa, Advances In Urban Rehabilitation And Sustainability, p: 153-158

Soyez D (2002) Unit 9: Industrial heritage i $n$ ol d i ndustrialised areas, htt $\mathrm{p}: / /$ www. uni -arburg. de/geographie/ virt ual/english/ brd/ module/ m2/u9. Htm

Tabak D (2011) Endüstriyel Miras Alanlarında Peyzaj Tasarımı Yaklaşımı: Yedikule Gazhanesi Örneği, İstanbul Teknik Üniversitesi, Fen Bilimleri Enstitüsü, Peyzaj Mimarlığı Anabilim Dalı, Yüksek Lisans Tezi, i̇stanbul.

Tolga HB (2006) Endüstriyel Alanların Dönüşümü, Kentsel Mekâna Etkileri: Beykoz Kundura ve Deri Fabrikası İçin Bir Dönüşüm Senaryosu. Yıldız Teknik Üniversitesi, Fen Bilimleri Enstitüsü, Mimarlık Anabilim Dalı, Yüksek Lisans Tezi, İstanbul.

Yöney N, Asiliskender B (2015) The Technology of an Early Reinforced Concrete Structure in Turkey: The Great Storehouse of the Kayseri Sümerbank Textile Factory (1932-1935). XIII International Forum, Heritage and Technology Mind Knowledge Experience, Capri 